\title{
Rare Earth-Indomethacinate Complexes with Heterocyclic Ligands: Synthesis and Photoluminescence Properties
}

\author{
João Batista M. Resende Filho, ${ }^{a}$ Paulo R. Santos, ${ }^{a}$ Juliana A. Vale, ${ }^{a}$ \\ Wagner M. Faustino, ${ }^{a}$ Danyelle S. Farias, ${ }^{b}$ Hermi F. Brito, ${ }^{c}$ Maria C. F. C. Felinto ${ }^{d}$ and \\ Ercules E. S. Teotonio ${ }^{*, a}$ \\ ${ }^{a}$ Departamento de Química, Universidade Federal da Paraíba (UFPB), \\ 58051-970 João Pessoa-PB, Brazil \\ ${ }^{b}$ Instituto Federal de Educação, Ciência e Tecnologia da Paraíba (IFPB), \\ Av. Primeiro de Maio, 720, 58015-435 João Pessoa-PB, Brazil \\ ${ }^{c}$ Departamento de Química Fundamental, Instituto de Química, Universidade de São Paulo (USP), \\ Av. Prof. Lineu Prestes, 748, 05508-900 São Paulo-SP, Brazil \\ ${ }^{d}$ Instituto de Pesquisas Energéticas e Nucleares (IPEN-CQMA), Av. Prof. Lineu Prestes, 2242, \\ 05508-000 São Paulo-SP, Brazil
}

\begin{abstract}
In this work, synthesis, characterization and photophysical properties of trivalent rare earth complexes with a nonsteroidal anti-inflammatory drug [the indomethacinate (indo), presenting formulas $\mathrm{RE}$ (indo) ${ }_{3}\left(\mathrm{H}_{2} \mathrm{O}\right)_{\mathrm{x}}\left(\mathrm{x}=3\right.$, for $\mathrm{Eu}^{3+}$ and $\mathrm{Gd}^{3+}$, and $\mathrm{x}=4$ for $\left.\mathrm{Tb}^{3+}\right)$, RE(indo) ${ }_{3}$ (bipy) and $\mathrm{RE}$ (indo) ${ }_{3}$ (phen) (bipy: 2,2'-bipyridine, and phen: 1,10-phenanthroline)] were investigated. Based on photoluminescent results, the intramolecular energy transfer process from $\mathrm{T}_{1}$ triplet states of indo, phen and bipy ligands to the ${ }^{5} \mathrm{D}_{0}$ emitting level of the $\mathrm{Eu}^{3+}$ ion in the coordination compounds is discussed. Accordingly, it is proposed two possible intramolecular energy transfer mechanisms between indomethacinate ligand and rare earth ions, which involve the participation of excited electronic states of the heterocyclic ligands as intermediate ones.
\end{abstract}

Keywords: indomethacin, rare earth, heterocyclics, photoluminescence, energy transfer

\section{Introduction}

In recent decades, metallotherapeutic drugs based on transition metal and trivalent rare earth ions have attracted considerable attention owing to their potential applications in medicine as anti-inflammatory, ${ }^{1}$ antitumor, ${ }^{2}$ antiproliferative, ${ }^{3}$ antifungal,${ }^{4,5}$ antiviral ${ }^{6,7}$ and antimicrobial. ${ }^{8}$ Many of these compounds present enhanced biomedical activity, reduced toxicity ${ }^{1}$ and diminished collateral effects as compared with non-coordinated parent drugs. Among various classes of metallotherapeutic drugs, those based on the nonsteroidal anti-inflammatory drugs (NSAIDs) from the carboxylate or oxicam families have received particular attention because of their great ability to coordinate to different metal ions, resulting thermodynamically and kinetically stable complexes.

*e-mail: teotonioees@quimica.ufpb.br
The molecular structures of NSAIDs are characterized by the presence of chromophore groups and low-lying triplet state with energy in the range of 20,000-25,000 $\mathrm{cm}^{-1}$, which may act as luminescent sensitizers for trivalent rare earth ions. ${ }^{9}$ Additionally, molecules of NSAIDs may act as multidentate ligands for $\mathrm{RE}^{3+}$ ion through their hard $\mathrm{N}-$ and $\mathrm{O}-$ sites. It is well-known that $\mathrm{RE}^{3+}$ ions play a wide range of roles in fluoroimmunoassay methods, ${ }^{10}$ therapy ${ }^{11}$ and as luminescent probe for biomolecules ${ }^{12}$ due to their unique spectroscopic properties such as narrow emission bands, high luminescence intensities and the long lifetimes of the ${ }^{2 S+1} L_{J}$ emitting levels. Furthermore, the rare earth ions may be indirectly excited via coordinated ligand (antenna effect) in a spectral region far from those where emission is generally monitored.

Recently, Zhou et al..$^{13}$ have investigated the structural and photophysical properties of two new rare earth complexes where carprofen has acted as effective luminescence 
sensitizer for the $\mathrm{Tb}^{3+}$ ion, but not for the $\mathrm{Eu}^{3+}$ ion. Luminescence properties of the $\mathrm{Tb}^{3+}$ complexes with ibuprofen and orthofen containing additional organic bases were also studied by Teslyuk et al. ${ }^{9}$ in order to propose an analytical method to determine NSAID drugs. The chemiluminescent method, based on $\mathrm{Eu}^{3+}$ emission for the determination of naproxen in pharmaceutical and urine, has been developed by Kaczmarek. ${ }^{14}$

Among NSAID drugs, indomethacin (1-(4-chlorobenzoyl)-5-methoxy-2-methyl- $1 H$-indole3 -acetic acid (Hindo)) (Figure 1) is considered one of the most clinically investigated. ${ }^{1}$ Its coordination complexes with transition metals have been extensively investigated in terms of structural and spectroscopic properties. ${ }^{15}$ Generally, these complexes present other donor ligands because indomethacinate (indo) cannot saturate the coordination sphere of the metal ions. In the case of the rare earth complexes, neutral ligands such as heteroaromatic and phosphine oxide ligands have been not only used for this purpose, but have been shown that they may also play an essential role in the luminescence sensitization that involves either a direct intramolecular energy transfer to the metal ion or an indirect mechanism via energy transfer to other ligands. The main evidences for this latter mechanism were reported for Eu ${ }^{3+}$-tris(diketonate) complexes ${ }^{16-18}$ however, the interligand energy transfer in rare earth complexes is still not clear.

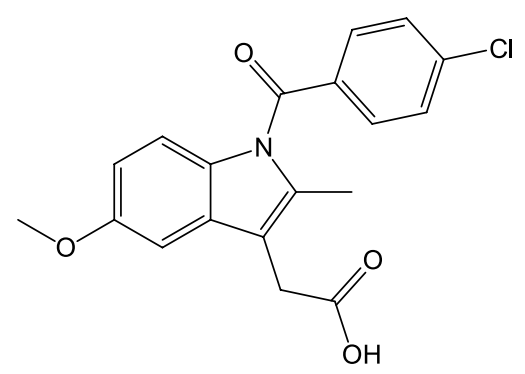

Figure 1. Molecular structural formula of the indomethacin ligand (Hindo).

In particular, excited triplet states of some heteroaromatic ligands are almost resonant with that for indomethacinate (indo) ligand, consequently, these states may contribute to an operative interligand energy transfer in which the heteroaromatic ligands act as energy acceptor from ionic ligands and, subsequently, transfer their energy to the trivalent rare earth ion increasing the luminescence intensity. Thus, the investigation of this intramolecular energy process may contribute to design of new highly luminescent complexes based on carboxylate ligands for different practical applications. Besides, up to now, to the best of our knowledge, no investigation has been carried out on the quantitative photophysical properties of the $\mathrm{RE}^{3+}$ coordination compounds in the solid state containing indomethacin.

Herein, it is reported the synthesis, characterization, intramolecular ligand-to-metal energy transfer and photophysical properties study of the $\mathrm{RE}^{3+}$ complexes (where $\mathrm{RE}^{3+}: \mathrm{Eu}^{3+}, \mathrm{Gd}^{3+}$ or $\mathrm{Tb}^{3+}$ ) with indomethacinate (indo) and ancillary heteroaromatic ligands (2,2'-bipyridine (bipy), and 1,10-phenanthroline (phen)), in the solid state. Photoluminescent properties of the $\mathrm{Eu}^{3+}$ complexes have been thoroughly investigated taking into account the radiative $\left(\mathrm{A}_{\mathrm{rad}}\right)$ and non-radiative $\left(\mathrm{A}_{\text {nrad }}\right)$ emission coefficients, experimental intensity parameters $\left(\Omega_{2}\right.$ and $\Omega_{4}$ ) and emission quantum efficiency $(\eta)$. Additionally, the synthesized complexes may be used to perform new methods for luminescence determination of NSAID drugs and potential application as target medicine. ${ }^{9}$

\section{Experimental}

\section{Materials}

The indomethacin ligand was extracted from the INDOCID $^{\circledR}$ drug using ethyl acetate as solvent and purified in a flash column chromatography on silica gel (Tedia, SiliaFlash ${ }^{\circledR}$ F60 40-63 $\mu$ m, 230-400 mesh), using a mixture of hexane and ethyl acetate (1:1) as eluent. The commercially available 2,2 '-bipyridine (bipy) 99\% and 1,10-phenanthroline (phen) monohydrated 99\% heteroaromatic ligands were purchased from Sigma-Aldrich and were used without previous purification. The rare earth chlorides $\left(\mathrm{RECl}_{3} \cdot 6 \mathrm{H}_{2} \mathrm{O}\right)$ were prepared by the reaction between their corresponding rare earth oxides, $\mathrm{RE}_{2} \mathrm{O}_{3}(99.999 \%)\left(\mathrm{RE}: \mathrm{Eu}^{3+}\right.$ and $\left.\mathrm{Gd}^{3+}\right)$ and $\mathrm{Tb}_{4} \mathrm{O}_{7}(99.999 \%)$ from Sigma-Aldrich, and concentrated hydrochloric acid (37\%, Merck) as reported in the literature. ${ }^{19,20}$

\section{Instrumentation}

$\mathrm{C}, \mathrm{H}$ and $\mathrm{N}$ analyses were performed on a microanalytical analyzer model 2400 (PerkinElmer). Infrared absorption spectra were recorded in a Shimadzu FTIR spectrophotometer model IRPrestige- 21 by using the technique of $\mathrm{KBr}$ pellets in the interval of $400-4000 \mathrm{~cm}^{-1}$. Thermogravimetric analyses (TGA) of the $\mathrm{RE}^{3+}$-indomethacinate complexes from room temperature to $900^{\circ} \mathrm{C}$ were conducted with a thermobalance model DTG-60H Shimadzu by using platinum crucibles with approximately $2 \mathrm{mg}$ of complexes. A dynamic synthetic air atmosphere $\left(50 \mathrm{~mL} \mathrm{~min}^{-1}\right)$ and a heating rate of $10{ }^{\circ} \mathrm{C} \mathrm{min}^{-1}$ were used as instrumental conditions. Steady-state luminescent spectra were acquired by using a Horiba 
JobinYvon Fluorolog-3 spectrofluorimeter presenting double grating $0.22 \mathrm{~m}$ monochromator (SPEX 1680) and a $450 \mathrm{~W}$ Xenon lamp as excitation source. Luminescence decay data were also collected by using a phosphorimeter SPEX 1934D accessory coupled to the Fluorolog-3 spectrofluorimeter.

\section{Synthetic methodology}

\section{Synthesis of the $\mathrm{RE}$ (indo) ${ }_{3}\left(\mathrm{H}_{2} \mathrm{O}\right)_{\times}$complexes}

A NaOH aqueous solution ( $\left.1 \mathrm{~mol} \mathrm{~L}^{-1}\right)$ was added slowly (dropwise) to a suspension of indomethacin ligand $(400.0 \mathrm{mg}$, $1.12 \mathrm{mmol}$ ) in $50 \mathrm{~mL}$ of water until the apparent $\mathrm{pH}$ value of ca. 7, followed by the dropwise addition of a $\mathrm{RECl}_{3} \cdot 6 \mathrm{H}_{2} \mathrm{O}$ aqueous solution $\left(0.37 \mathrm{mmol}: 135.6 \mathrm{mg}\left(\mathrm{EuCl}_{3} \cdot 6 \mathrm{H}_{2} \mathrm{O}\right)\right.$, $137.4 \mathrm{mg}\left(\mathrm{GdCl}_{3} \cdot 6 \mathrm{H}_{2} \mathrm{O}\right)$ and $\left.138.2 \mathrm{mg}\left(\mathrm{TbCl}_{3} \cdot 6 \mathrm{H}_{2} \mathrm{O}\right)\right)$, yielding immediately a yellow solid precipitate. The powder samples were filtered, washed thoroughly with cooled water and dried under reduced pressure $\left(358.9 \mathrm{mg}, 76 \%\right.$ for $\mathrm{Eu}^{3+}$; $312.8 \mathrm{mg}, 66 \%$ for $\mathrm{Gd}^{3+}$; and $308.6 \mathrm{mg}, 65 \%$ for $\mathrm{Tb}^{3+}$ ); $\mathrm{CHN}$ anal. calcd. for $\mathrm{C}_{57} \mathrm{H}_{51} \mathrm{Cl}_{3} \mathrm{EuN}_{3} \mathrm{O}_{15}$ (1): C, 53.64; H, 4.03; $\mathrm{N}, 3.29$; found: C, 53.46; H, 4.17; N, 3.17; FTIR (KBr) $\mathrm{v} / \mathrm{cm}^{-1} 3390 \mathrm{~m}, 3088 \mathrm{w}, 2992 \mathrm{w}, 2926 \mathrm{~m}, 2849 \mathrm{w}, 2833 \mathrm{w}$, 1682s, 1591s, 1545s, 1477s, 1416s, 1402s, 1323s, 1229s, 1090m, 1014w, 924w, 835w, 754w; CHN anal. calcd. for $\mathrm{C}_{57} \mathrm{H}_{51} \mathrm{Cl}_{3} \mathrm{GdN}_{3} \mathrm{O}_{15}$ (2): C, 53.42; H, 4.01; N, 3.28; found: C, 53.49; H, 4.15; N, 3.35; FTIR (KBr) v / cm $\mathrm{cm}^{-1} 3418 \mathrm{~m}$, 3088w, 3069w, 2994w, 2955w, 2928m, 2833w, 1682s, 1591s, $1553 \mathrm{~s}, 1477 \mathrm{~s}, 1435 \mathrm{~s}, 1400 \mathrm{~s}, 1369 \mathrm{~s}, 1323 \mathrm{~s}, 1230 \mathrm{~s}, 1148 \mathrm{~m}$, 1090m, 1070m, 1036m, 1014w, 926w, 835w, 754w; CHN anal. calcd. for $\mathrm{C}_{57} \mathrm{H}_{53} \mathrm{Cl}_{3} \mathrm{TbN}_{3} \mathrm{O}_{16}$ (3): C, 52.61; H, 4.11; $\mathrm{N}, 3.23$; found: C, 52.26; H, 4.08; N, 3.03; FTIR (KBr) $\mathrm{v} / \mathrm{cm}^{-1} 3424 \mathrm{~m}, 3088 \mathrm{w}, 3067 \mathrm{w}, 2994 \mathrm{w}, 2928 \mathrm{~m}, 2849 \mathrm{~m}$, $2833 \mathrm{w}, 1682 \mathrm{~s}, 1591 \mathrm{~s}, 1553 \mathrm{~s}, 1477 \mathrm{~s}, 1437 \mathrm{~s}, 1400 \mathrm{~s}, 1321 \mathrm{~s}$, $1229 \mathrm{~s}, 1148 \mathrm{~m}, 1090 \mathrm{~m}, 924 \mathrm{~m}, 835 \mathrm{~m}, 754 \mathrm{~m}$.

\section{Synthesis of the $\mathrm{RE}$ (indo) ${ }_{3}$ (bipy) complexes}

To a solution of bipy (37.4 mg, $0.24 \mathrm{mmol})$ in ethyl acetate $(10 \mathrm{~mL})$ was added dropwise a solution of $\mathrm{RE}(\text { indo })_{3}\left(\mathrm{H}_{2} \mathrm{O}\right)_{\mathrm{x}}$ complexes $(0.24 \mathrm{mmol}: 300.0 \mathrm{mg}$ for $\mathrm{Eu}^{3+}, 307.5 \mathrm{mg}$ for $\mathrm{Gd}^{3+}$, and $308.0 \mathrm{mg}$ for $\mathrm{Tb}^{3+}$ complex) in ethyl acetate $(40 \mathrm{~mL})$. A precipitate (yellow powder) was obtained after the solvent evaporation. The product was thoroughly washed with cooled ethyl acetate $(\mathrm{ca} .10 \mathrm{~mL})$, filtered and dried under reduced pressure resulting in yellow solid $(281.5 \mathrm{mg}, 84 \%$ for $\mathrm{Eu}^{3+} ; 289.2 \mathrm{mg}, 86 \%$ for $\mathrm{Gd}^{3+}$; and $276.2 \mathrm{mg}, 82 \%$ for $\mathrm{Tb}^{3+}$ ). Although the complexes are very soluble in several solvents (dichloromethane, chloroform, ethyl acetate, acetone, toluene, etc.), and all attempts to obtain single crystals were unsuccessful; $\mathrm{CHN}$ anal. calcd. for $\mathrm{C}_{67} \mathrm{H}_{53} \mathrm{Cl}_{3} \mathrm{EuN}_{5} \mathrm{O}_{12}$ (4): C, 58.38; H, 3.88; N, 5.08; found
(\%): C, 57.76; H, 3.84; N, 5.07; FTIR (KBr) $v / \mathrm{cm}^{-1}$ 3428w, 3069w, 3042w, 2992w, 2926w, 2832w, 1682s, $1601 \mathrm{~s}, 1566 \mathrm{~s}, 1477 \mathrm{~s}, 1458 \mathrm{~s}, 1437 \mathrm{~s}, 1398 \mathrm{~s}, 1321 \mathrm{~s}, 1227 \mathrm{~s}$, $1148 \mathrm{~m}, 1088 \mathrm{~m}, 1036 \mathrm{~m}, 924 \mathrm{w}, 835 \mathrm{~m}, 756 \mathrm{~m}$; CHN anal. calcd. for $\mathrm{C}_{67} \mathrm{H}_{53} \mathrm{Cl}_{3} \mathrm{GdN}_{5} \mathrm{O}_{12}(\mathbf{5})$ : C, 58.15; H, 3.86; N, 5.06; found: C, 57.26; H, 4.24; N, 4.93; FTIR (KBr) $v / \mathrm{cm}^{-1} 3428 \mathrm{w}, 3071 \mathrm{w}, 2990 \mathrm{w}, 2928 \mathrm{w}, 2849 \mathrm{w}, 2832 \mathrm{w}$, $1682 \mathrm{~s}, 1601 \mathrm{~s}, 1566 \mathrm{~m}, 1477 \mathrm{~s}, 1458 \mathrm{~m}, 1437 \mathrm{~s}, 1321 \mathrm{~s}$, $1227 \mathrm{~s}, 1148 \mathrm{~m}, 1088 \mathrm{~m}, 1036 \mathrm{~m}, 1014 \mathrm{~m}, 924 \mathrm{w}, 835 \mathrm{~m}$, 756m; CHN anal. calcd. for $\mathrm{C}_{67} \mathrm{H}_{53} \mathrm{Cl}_{3} \mathrm{TbN}_{5} \mathrm{O}_{12}(6)$ : C, 58.08; H, 3.86; N, 5.05; found: C, 57.26; H, 4.36; N, 4.96; FTIR (KBr) v / cm ${ }^{-1} 3428 w, 3084 w, 2990 w, 2926 w$, 2849w, 2833w, 1682s, 1603s, 1564s, 1477s, 1437s, 1317s, $1227 \mathrm{~s}, 1148 \mathrm{~m}, 1090 \mathrm{~m}, 1036 \mathrm{~m}, 926 \mathrm{~m}, 835 \mathrm{~m}, 756 \mathrm{~m}$.

\section{Synthesis of the $\mathrm{RE}$ (indo) ${ }_{3}$ (phen) complexes}

To a solution of phen monohydrated $(47.5 \mathrm{mg}$, $0.24 \mathrm{mmol})$ in ethyl acetate $(10 \mathrm{~mL})$ was added dropwise a solution of $\mathrm{RE}(\text { indo })_{3}\left(\mathrm{H}_{2} \mathrm{O}\right)_{\mathrm{x}}$ complexes $(0.24 \mathrm{mmol}$ : $300.0 \mathrm{mg}\left(\mathrm{Eu}^{3+}\right), 307.5 \mathrm{mg}\left(\mathrm{Gd}^{3+}\right)$ and $\left.308.0 \mathrm{mg}\left(\mathrm{Tb}^{3+}\right)\right)$ in ethyl acetate $(40 \mathrm{~mL})$. A precipitate (yellow powder) was obtained after the solvent evaporation. The product was thoroughly washed with cooled ethyl acetate (ca. $10 \mathrm{~mL}$ ), filtered and dried under reduced pressure resulting in yellow solid (279.5 mg, 82\% for $\mathrm{Eu}^{3+} ; 280.5 \mathrm{mg}, 82 \%$ for $\mathrm{Gd}^{3+}$; and $267.2 \mathrm{mg}, 78 \%$ for $\mathrm{Tb}^{3+}$ ). Although the complexes are very soluble in several solvents (dichloromethane, chloroform, ethyl acetate, acetone, toluene, etc.), and all attempts to obtain single crystals were unsuccessful; $\mathrm{CHN}$ anal. calcd. for $\mathrm{C}_{69} \mathrm{H}_{53} \mathrm{Cl}_{3} \mathrm{EuN}_{5} \mathrm{O}_{12}$ (7): C, 59.09; $\mathrm{H}, 3.81 ; \mathrm{N}, 4.99$; found: C, 58.73; H, 3.98; N, 5.55; FTIR (KBr) v/ $\mathrm{cm}^{-1} 3437 \mathrm{w}$, 3076w, 2992w, 2926w, 2832w, 1680s, 1607s, 1553m, 1477s, $1427 \mathrm{~s}, 1356 \mathrm{~s}, 1325 \mathrm{~s}, 1227 \mathrm{~s}, 1148 \mathrm{~m}, 1088 \mathrm{~m}, 1068 \mathrm{~m}, 920 \mathrm{~m}$, 833m, 754m; CHN anal. calcd. for $\mathrm{C}_{69} \mathrm{H}_{53} \mathrm{Cl}_{3} \mathrm{GdN}_{5} \mathrm{O}_{12}(\mathbf{8})$ : C, 58.87; H, 3.79; N, 4.97; found: C, 57.63; H, 4.24; N, 4.86; FTIR (KBr) v / cm $\mathrm{c}^{-1} 3447 \mathrm{~m}, 3078 \mathrm{w}, 2992 \mathrm{w}, 2953 \mathrm{w}$, 2953w, 2832w, 1678s, 1607s, 1589s, 1556m, 1477s, 1427s, $1398 \mathrm{~s}, 1356 \mathrm{~s}, 1229 \mathrm{~s}, 1144 \mathrm{~m}, 1090 \mathrm{~m}, 1069 \mathrm{~m}, 922 \mathrm{w}, 837 \mathrm{~m}$, 754m. CHN anal. calcd. for $\mathrm{C}_{69} \mathrm{H}_{53} \mathrm{Cl}_{3} \mathrm{TbN}_{5} \mathrm{O}_{12}$ (9): C, 58.80; H, 3.79; N, 4.97; found: C, 57.36; H, 3.91; N, 4.85; FTIR (KBr) $v / \mathrm{cm}^{-1} 3597 \mathrm{w}, 3428 \mathrm{w}, 3078 \mathrm{w}, 2992 \mathrm{w}, 2953 \mathrm{w}, 2928 \mathrm{w}$, 2832w, 1678s, 1609s, 1589s, 1557m, 1477s, 1427s, 1356s, 1325s, 1229s, 1148m, 1090m, 922m, 835m, 754m.

\section{Results and Discussion}

\section{Synthesis and characterization}

Elemental analysis data of the rare earth indomethacinate complexes are in agreement with the ratios metal:indo:water and metal:indo:heteroaromatic equal to 1:3:3 for hydrated 
complexes (1 and 2), 1:3:4 for hydrated complex (3) and 1:3:1 for rare earth complexes (4-9) which contain bipy and phen as ancillary ligands.

FTIR spectrum for indomethacin ligand extracted from the INDOCID $^{\circledR}$ drug is in agreement (Figure S1 in the Supplementary Information (SI) section). Figure 2 shows the FTIR spectra for the $\mathrm{Eu}^{3+}$-indomethacinate complexes, while FTIR spectra for $\mathrm{Gd}^{3+}$ and $\mathrm{Tb}^{3+}$ are presented in Figures S2 and $\mathrm{S} 3$ in the SI section. In general, the absorption spectra for the $\mathrm{RE}^{3+}$ complexes (1-3) exhibit a broad band in the range of $2600-3400 \mathrm{~cm}^{-1}$ that is assigned to the $\mathrm{O}-\mathrm{H}$ stretching of the water molecules. As can be seen, this band is not present in the vibrational spectra for the complexes containing the heteroaromatic ancillary ligands, indicating that water molecules have been substituted by neutral ligands. The characteristic absorption bands assigned to the carboxylic group $(\mathrm{COOH})$ of the Hindo free ligand, e.g., $v(\mathrm{O}-\mathrm{H})$ at $3300 \mathrm{~cm}^{-1}$ and $v(\mathrm{C}=\mathrm{O})$ at $1734 \mathrm{~cm}^{-1}$, have been substituted by the intense absorption bands assigned to $\mathrm{v}_{\mathrm{as}}(\mathrm{COO})$ (at $\left.1613 \mathrm{~cm}^{-1}\right)$ and $\mathrm{v}_{\mathrm{s}}(\mathrm{COO})\left(\right.$ at $\left.1416 \mathrm{~cm}^{-1}\right)$ of the carboxylate group of the $\mathrm{RE}^{3+}$ complexes (2). Furthermore, the values for $\Delta\left[\Delta_{\mathrm{as}}(\mathrm{COO})-\Delta_{\mathrm{s}}(\mathrm{COO})\right]$ are falling in the range of $197 \mathrm{~cm}^{-1}$ for all the complexes (1-9), indicating that indo ligand is coordinated to the $\mathrm{RE}^{3+}$ as chelating or bridging mode. ${ }^{21-23}$ These results strongly suggest that those complexes are either binuclear or coordination polymers. Moreover, the absorption bands around 1468 and $1423 \mathrm{~cm}^{-1}$ indicate that bipy and phen heteroaromatic ligands are coordinated to the metal ions through their nitrogen atoms. ${ }^{16,24}$

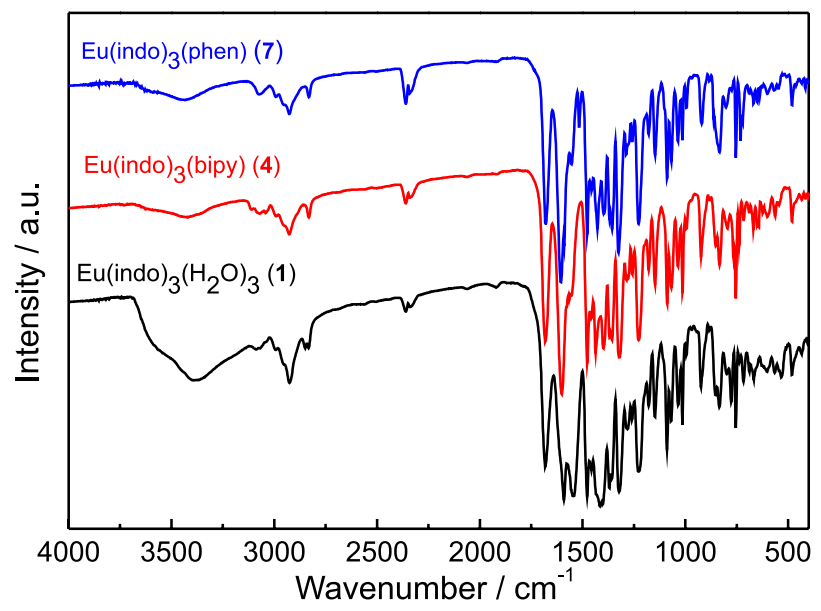

Figure 2. FTIR absorption spectra of the $\mathrm{Eu}^{3+}$ complexes (1, $\mathbf{4}$ and 7) recorded in the range of $4000-400 \mathrm{~cm}^{-1}$ in $\mathrm{KBr}$ pellets.

The presence of water molecules in the complexes (1-3) was also characterized by thermogravimetric analysis. TGA curves (Figure 3) present a weight loss around 3.5\% in the temperature interval between $60-150{ }^{\circ} \mathrm{C}$ that is attributed to the release of three water molecules for the complex (1) (similar to complex (2), see Figure S4 in the SI file). This result is similar to the thermal decomposition for the $\mathrm{Ce}(\mathrm{indo})_{3}\left(\mathrm{H}_{2} \mathrm{O}\right)_{3}$ complex reported in reference. ${ }^{15}$ Figure 3 also displays the TGA curves for the $\mathbf{E u}^{3+}$ complexes (4 and $\mathbf{7}$ ) containing bipy and phen ligands.

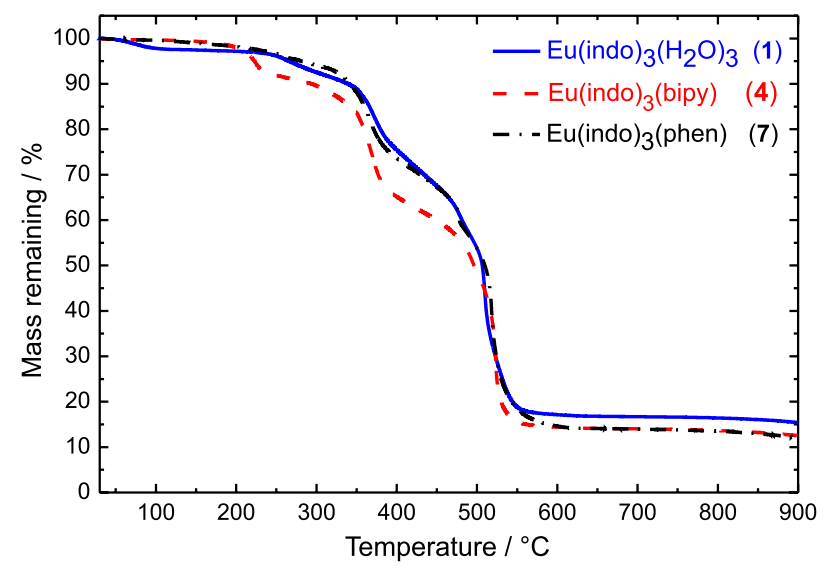

Figure 3. TGA curves of the complexes $(\mathbf{1}, \mathbf{4}$ and $\mathbf{7})$ recorded in the interval of $25-900{ }^{\circ} \mathrm{C}$, using dynamic synthetic air atmosphere $\left(50 \mathrm{~mL} \mathrm{~min}^{-1}\right)$ and a heating rate of $10^{\circ} \mathrm{C} \mathrm{min}$.

TGA curves for other coordination compounds are shown in Figures S4 and S5 in the SI section. For the complex (3), TGA curve shows a weight loss around 5\% in the same temperature interval that is attributed to the release of four water molecules which corroborate with the $\mathrm{CHN}$ elemental analysis data. The resulting anhydrous compounds undergo thermal decomposition in successive steps that occur from 230 to $670{ }^{\circ} \mathrm{C}$. In contrast to the hydrated complexes, TGA curves for the complexes (4) to (9) do not exhibit any weight loss until $150{ }^{\circ} \mathrm{C}$, confirming the anhydrous form of these coordination compounds.

The coordination compounds (3, 6 and 9) present successive steps that take place in the range of $300-750{ }^{\circ} \mathrm{C}$, starting with a weight loss that corresponds to the release of the phen ligand. The TGA curves show that complexes with bipy ligand $(\mathbf{2}, \mathbf{5}$ and $\mathbf{8})$ are less stable than those ones containing phen ligand (3, $\mathbf{6}$ and $\mathbf{9})$. The first weight loss of these complexes (around $170{ }^{\circ} \mathrm{C}$ ) may be assigned to the release of the bipy ligand. However, no well-defined level is observed in the TGA curves owing to the subsequent decomposition of the $\mathrm{RE}(\mathrm{indo})_{3}$ products. The final products remain stable until $900{ }^{\circ} \mathrm{C}$ for the thermal decomposition of all complexes, which can be assigned to the corresponding rare earth oxide, $\mathrm{RE}_{2} \mathrm{O}_{3}(\mathrm{RE}$ : $\mathrm{Eu}$ and $\mathrm{Gd})$ and $\mathrm{Tb}_{4} \mathrm{O}_{7}$.

\section{Phosphorescent behavior}

The emission spectra of the $\mathrm{Gd}^{3+}$ complexes $(\mathbf{2}, \mathbf{5}$ and 8) were recorded with excitation on the $S_{0} \rightarrow S_{1}$ 
indomethacinate centered transition at $350 \mathrm{~nm}$ (Figure 4), showing two overlapped broad bands with maxima around 420 (blue region) and $500 \mathrm{~nm}$ (green region) assigned to the fluorescence $\left(S_{1} \rightarrow S_{0}\right)$ and phosphorescence $\left(T \rightarrow S_{1}\right)$ intraligand transitions, respectively.

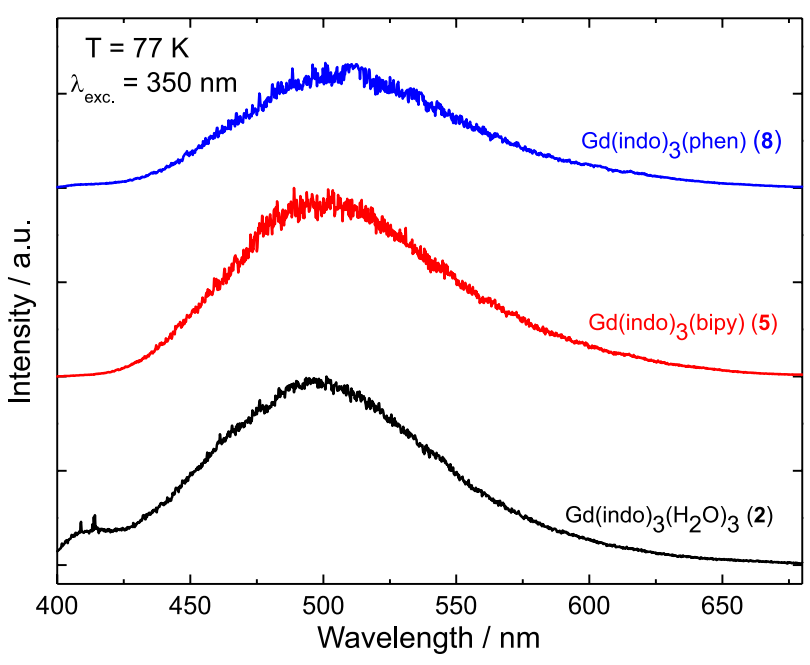

Figure 4. Phosphorescence spectra of the $\mathrm{Gd}^{3+}$ complexes $(\mathbf{2}, \mathbf{5}$ and $\mathbf{8})$, in solid state, recorded at liquid nitrogen temperature in spectral range of $400-700 \mathrm{~nm}$, under excitation at $350 \mathrm{~nm}$.

Since the highest intensity band is that due to the phosphorescence, the $\mathrm{Gd}^{3+}$-indomethacinate complexes present green emission color under UV radiation excitation. Interestingly, no obvious difference between the emission spectra profiles of the $\mathrm{Gd}^{3+}$ complexes $(\mathbf{5}$ and $\mathbf{8})$ and that for the precursor complex, 2, is observed, indicating that photoluminescence properties of all the $\mathrm{Gd}^{3+}$ complexes are mainly due to the indomethacinate ligand coordinated to the $\mathrm{RE}^{3+}$ ion. For these coordination compounds, the indomethacinate triplet state $\left(\mathrm{T}_{1}\right)$ was determined taking into account the $0-0$ phonon transition from the timeresolved phosphorescence spectra recorded with time delay of $0.04 \mathrm{~ms}$ (Figure S6 in the SI section).

The absence of the short-lived fluorescence emission band around $420 \mathrm{~nm}$ in those spectra (Figure 4) allowed for a more precise determination of the $\mathrm{T}_{1}$ state energies, as following: $22,124,21,882$ and $21,552 \mathrm{~cm}^{-1}$ for the $\mathrm{Gd}(\text { indo })_{3}\left(\mathrm{H}_{2} \mathrm{O}\right)_{3}(\mathbf{2})$, Gd(indo) ${ }_{3}\left(\right.$ bipy) (5) and $\mathrm{Gd}(\text { indo) })_{3}($ phen) (8) complexes, respectively. These optical data indicate that triplet states of indo ligand should be in a good resonance condition of the emitting levels of the $\mathrm{Eu}^{3+}$ ion, acting as an efficient antenna for europium complexes. ${ }^{16}$

\section{Luminescence spectra of the $\mathrm{Eu}^{3+}$}

As to the emission monitored on the intraconfigurational ${ }^{5} \mathrm{D}_{0} \rightarrow{ }^{7} \mathrm{~F}_{2}$ hypersensitive transition centered on the $\mathrm{Eu}^{3+}$ ion (at approximately $612 \mathrm{~nm}$ ), all excitation spectra for solid-state of the complexes (1, $\mathbf{4}$ and 7) exhibit similar spectral profiles. These spectra (Figure 5) present a strong broad band in the range of $250-450 \mathrm{~nm}$ assigned to the $S_{0} \rightarrow S_{1}$ transition belong to indo ligand, indicating that even in the complexes with bipy and phen, the luminescence sensitization mechanism of the $\mathrm{Eu}^{3+}$ ion started with radiation absorption by indomethacinate ligand. However, minor contributions due to the absorption from heterocyclic ligands are observed. It is worth noting that this band exhibits higher intensity than those ones from the intraconfigurational ${ }^{7} \mathrm{~F}_{0} \rightarrow{ }^{2 S+1} \mathrm{~L}_{\mathrm{J}}$ transitions at around 468 and $525 \mathrm{~nm}$, confirming the potential ability of the ligand to transfer energy to the $\mathrm{Eu}^{3+}$ ion.

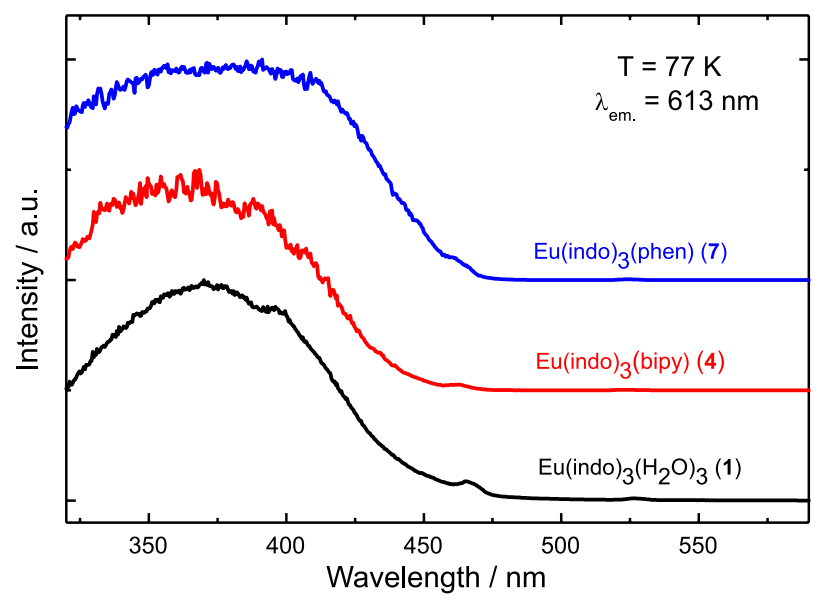

Figure 5. Excitation spectra of the $\mathrm{Eu}^{3+}$ complexes $(\mathbf{1}, \mathbf{4}$ and $\mathbf{7})$, in solid state, recorded at $77 \mathrm{~K}$ with emission monitored at $613 \mathrm{~nm}$.

The emission spectra of all the $\mathrm{RE}^{3+}$ coordination compounds were recorded at 298 and $77 \mathrm{~K}$, upon excitation on the ligand $S_{0} \rightarrow S_{1}$ transition (at $350 \mathrm{~nm}$ ) of the indomethacinate ligand (Figure 6). Under this condition, all the $\mathrm{Eu}^{3+}$-indomethacinate coordination compounds $(\mathbf{1}, \mathbf{4}$ and $\mathbf{7})$ display high red luminescence at $77 \mathrm{~K}$. A qualitative analysis shows that the $\mathrm{Eu}^{3+}$ complexes with ancillary heteroaromatic ligands (4 and 7) exhibit significantly higher luminescent intensities than the hydrated complex (1).

The emission spectra of the complex (1) in the range of 430-720 nm recorded at 298 and $77 \mathrm{~K}$ exhibit different spectral profiles (Figure 6). When recorded at $298 \mathrm{~K}$, a broad band arising from intraligand transition is observed, that is only partially quenched in the emission spectrum recorded at $77 \mathrm{~K}$. This band overlaps the standard set of well-resolved narrow emission bands owing to the $\mathrm{Eu}^{3+}$ centered transitions: ${ }^{5} \mathrm{D}_{0} \rightarrow{ }^{7} \mathrm{~F}_{0}(579 \mathrm{~nm}),{ }^{5} \mathrm{D}_{0} \rightarrow{ }^{7} \mathrm{~F}_{1}$ $(589 \mathrm{~nm}),{ }^{5} \mathrm{D}_{0} \rightarrow{ }^{7} \mathrm{~F}_{2}(613 \mathrm{~nm}),{ }^{5} \mathrm{D}_{0} \rightarrow{ }^{7} \mathrm{~F}_{3}(635 \mathrm{~nm})$ and ${ }^{5} \mathrm{D}_{0} \rightarrow{ }^{7} \mathrm{~F}_{4}(717 \mathrm{~nm}) .{ }^{24}$ On the other hand, one of the 

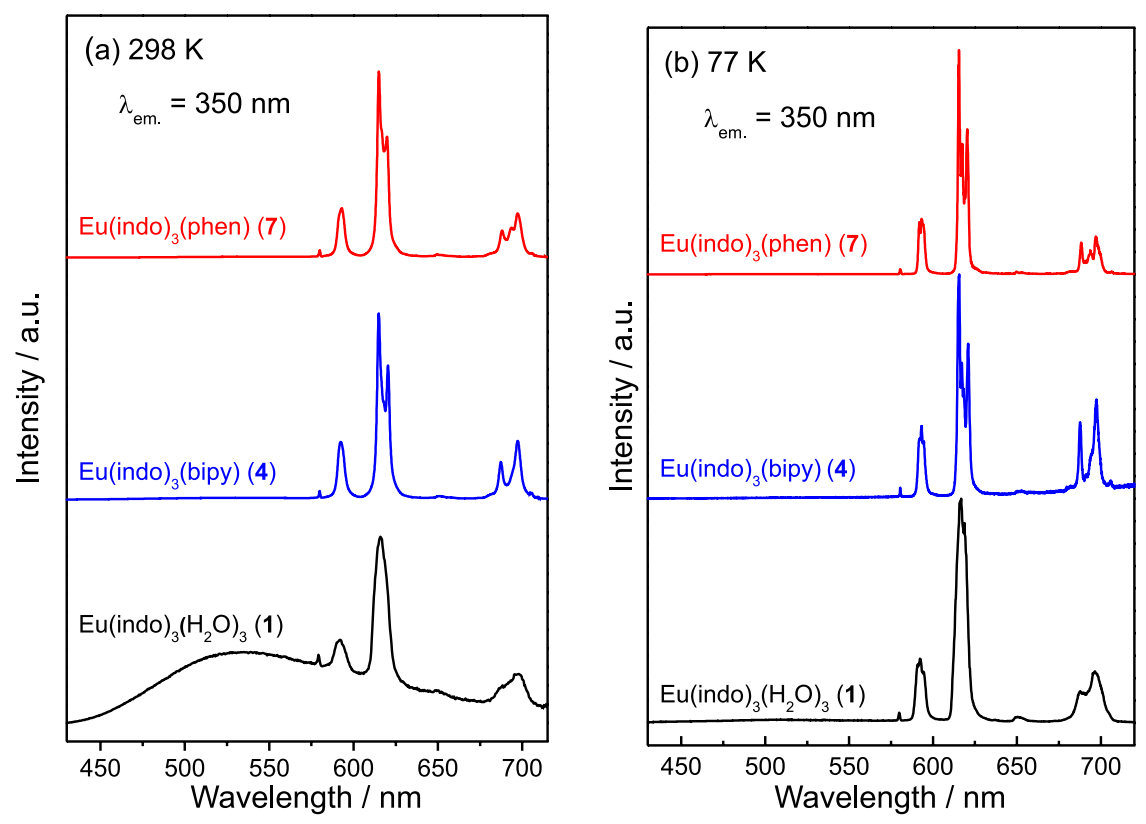

Figure 6. Emission spectra of the $\mathrm{Eu}^{3+}$ complexes $\left(\mathbf{1}, \mathbf{4}\right.$ and 7), in solid state, measured at (a) $298 \mathrm{~K}$ and (b) $77 \mathrm{~K}$, under excitation on the $\mathrm{S}_{1}$ state of the indomethacinate ligand at $350 \mathrm{~nm}$.

main features to be outlined from the photoluminescent spectra for complexes $\mathbf{4}$ and 7, both recorded at 298 and $77 \mathrm{~K}$, is the absence of the broad emission bands due to the indomethacinate fluorescence or phosphorescence. All of these photoluminescence spectra display similar spectral profile, in which only the intraconfigurational- $4 \mathrm{f}^{6}$ transitions are observed, being dominated by the well-characterized hypersensitive ${ }^{5} \mathrm{D}_{0} \rightarrow{ }^{7} \mathrm{~F}_{2}$ transition allowed by forced electric dipole mechanism. It is also important to note the lower relative intensity ratio between the ${ }^{5} \mathrm{D}_{0} \rightarrow{ }^{7} \mathrm{~F}_{2}$ and ${ }^{5} \mathrm{D}_{0} \rightarrow{ }^{7} \mathrm{~F}_{1}$ transitions in comparison with those for low symmetry $\mathrm{Eu}^{3+}$ tris- $\beta$-diketonate coordination compounds containing the bipy and phen, or their derivative ligands. ${ }^{25,26}$ These results altogether suggest that a chemical environment around the rare earth ion is close to $C_{n}$ or $C_{n v}$ symmetry.

Although indomethacinate ligand dominates the antenna effect, emission data give evidences that excited states centered on the heterocyclic ligands (bipy and phen) can also play an important role as intermediate states in the intramolecular energy transfer from indomethacinate ligand to $\mathrm{Eu}^{3+}$ ion. A possible explanation for this behavior lies in the fact of heterocyclic ligands present their low-lying excited triplet states close in energy to the $T_{1}$ triplet excited state of the indomethacinate ligand. It is also close in energy to ${ }^{5} \mathrm{D}_{0}$ (ca. $17293 \mathrm{~cm}^{-1}$ ) and ${ }^{5} \mathrm{D}_{1}$ (ca. $19027 \mathrm{~cm}^{-1}$ ) emitting levels of the $\mathrm{Eu}^{3+}$ ion. According to the literature, the intramolecular energy transfer in the $\mathrm{Eu}^{3+}$-indomethacinate complexes can be divided into two mechanisms, which is shown in Figure 7.27,28

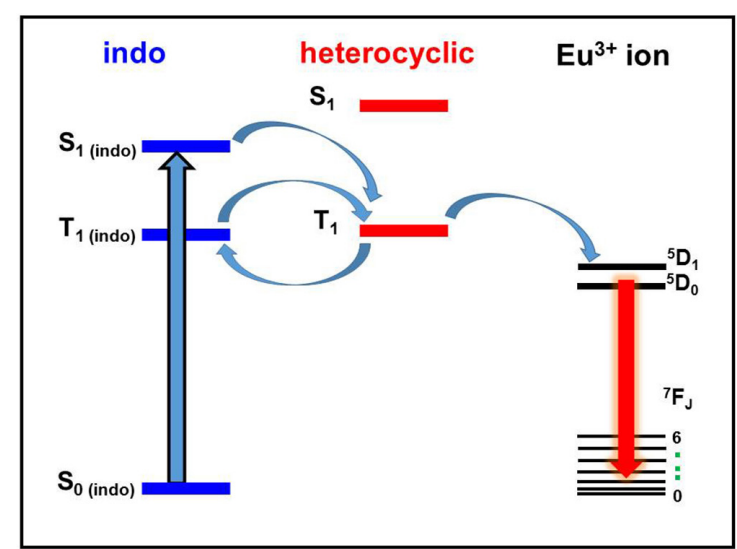

Figure 7. Partial energy level diagrams of the intramolecular energy transfer mechanisms for $\mathrm{Eu}^{3+}$-indomethacinate complexes containing heterocyclic ligands. $S_{1}$ and $T_{1}$ represent excited singlet and triplet states, respectively.

For the first mechanism, indomethacinate ligand absorbs energy being excited to its $S_{1}$ states, and subsequently transfers this energy to the $T_{1}$ excited state belonging to heterocyclic ligand (Figure 7). Therefore, this latter ligand undergoes energy transfer from the intraligand triplet state to ${ }^{5} \mathrm{D}_{1}$ or ${ }^{5} \mathrm{D}_{0}$ levels of the $\mathrm{Eu}^{3+}$ ion $\left(\mathrm{T}_{1} \rightarrow{ }^{5} \mathrm{D}_{1} \rightarrow{ }^{5} \mathrm{D}_{0}\right)$, followed by radiative and non-radiative deactivation centered on the central metal ion $\left({ }^{5} \mathrm{D}_{0} \rightarrow{ }^{5} \mathrm{~F}_{\mathrm{J}}\right)$. By means of the second mechanism, indomethacinate ligand absorbs energy being excited to its singlet state $S_{1}$, which undergoes intersystem crossing energy to the own $\mathrm{T}_{1}$ state and transfers to the triplet excited level $\left(\mathrm{T}_{1}\right)$ of the heterocyclic ligand, followed by sensitization of the excited levels of the $\mathrm{Eu}^{3+}$ (Figure 7). In order to give an insight into the proposed 
mechanisms above, it is listed the energies corresponding to the $S_{1}$ and $T_{1}$ excited states for all the coordinated ligands: $S_{1}$ (indo) at $29,411 \mathrm{~cm}^{-1}, T_{1}$ (indo) at $21,790 \mathrm{~cm}^{-1}$, $\mathrm{S}_{1}$ (phen) at $32,894 \mathrm{~cm}^{-1}, \mathrm{~T}_{1}$ (phen) at $22,100 \mathrm{~cm}^{-1}, \mathrm{~S}_{1}$ (bipy) at $30,300 \mathrm{~cm}^{-1}$ and $\mathrm{T}_{1}$ (bipy) at $22,100 \mathrm{~cm}^{-1}$.

Following the standard methodology described by Sá et al. ${ }^{28}$ the photophysical properties of the $\mathrm{Eu}^{3+}$ ion into the novel complexes were quantitatively investigated. The spectroscopic parameters $\left(\mathrm{A}_{\mathrm{rad}}\right)$, JuddOfelt intensity parameters $\left(\Omega_{\lambda}, \lambda=2,4\right.$ and 6$)$ and emission quantum efficiency $(\eta)$ were directly determined from the photophysical data.

The radiative rates $\left(\mathrm{A}_{\mathrm{rad}}\right)$ of the $\mathrm{Eu}^{3+}$-indomethacinate complexes were determined taking into account the following equation: ${ }^{27}$

$\mathrm{A}_{\mathrm{rad}}=\sum_{\mathrm{J}=2,4,6} \mathrm{~A}_{0 \mathrm{~J}}=\sum_{\mathrm{J}=2,4,6}\left(\frac{\mathrm{S}_{0 \mathrm{~J}}}{\mathrm{~S}_{01}}\right)\left(\frac{\sigma_{01}}{\sigma_{0 \mathrm{~J}}}\right) \mathrm{A}_{01}$

where, $\mathrm{A}_{01}=0.31 \times 10^{-11} \eta^{3} \sigma^{3}$ and $\mathrm{A}_{0 \mathrm{~J}}$ is the radiative rates assigned to the intraconfigurational ${ }^{5} \mathrm{D}_{0} \rightarrow{ }^{7} \mathrm{~F}_{1}$ and ${ }^{5} \mathrm{D}_{0} \rightarrow{ }^{7} \mathrm{~F}_{\mathrm{J}}\left(\mathrm{J}=2,4\right.$ and 6) transitions, respectively. $\mathrm{S}_{0 \mathrm{~J}}$ and $\sigma_{0 \mathrm{~J}}$ correspond, respectively, to the integrated intensities and barycenters of the intraconfigurational transitions. Each Judd-Ofelt intensity parameters $\left(\Omega_{\lambda}, \lambda=2,4\right.$ and 6) of the $\mathrm{Eu}^{3+}$ ion presents a direct correlation with the $\mathrm{A}_{0 \mathrm{~J}}$ for a particular ${ }^{5} \mathrm{D}_{0} \rightarrow{ }^{7} \mathrm{~F}_{\mathrm{J}}$ transition, which is expressed by the well-known equation reported in our previous work. ${ }^{29}$

Importantly, luminescence quantum efficiency $(\eta)$ for the $\mathrm{Eu}^{3+}$-indomethacinate complexes was determined from the product $\eta=\mathrm{A}_{\text {rad }} \tau$, where $\tau$ is the luminescence decay lifetime of the ${ }^{5} \mathrm{D}_{0}$ emitting level. The values of $\tau$ were determined by the well-adjusted single-exponential luminescence decay curves of the $\mathrm{Eu}^{3+}$ complexes upon excitation and emission monitored at 350 and $613 \mathrm{~nm}$, respectively. The non-radiative rate, $A_{\text {nrad }}$, was estimated from the difference between the value of $A_{\text {total }}(1 / \tau)$ and $A_{\text {rad }}$ value.

Table 1 presents the spectroscopic parameters obtained for all three $\mathrm{Eu}^{3+}$-indomethacinate compounds at 298 and
$77 \mathrm{~K}$. As can be seen, the values of radiative rates for the complexes are comparable, indicating that no marked change occurs in the symmetry around the central metal ion when water molecules are substituted by the heterocyclic ligands or when the temperature is changed. On the other hand, a significant decrease in non-radiative rates $\left(\mathrm{A}_{\text {nrad }}\right)$ is observed when water molecules are replaced by those ligands, which is expected due to the ability of water molecules act as luminescence quenchers via multiphonon decay mechanism. ${ }^{30}$

$\mathrm{Eu}^{3+}$ complex (1) presents a considerably high dependence of $A_{\text {nrad }}$ on the temperature in comparison with all of the other complexes investigated in this work (Table 1). This result suggests that there is the multi-phonon luminescent quenching effect, promoted by water molecules, and the additional luminescence quenching channel, probably a ligand-to-metal charge transfer state (LMCT). As a result, the luminescence quantum efficiency for the hydrated $\mathrm{Eu}^{3+}$-indomethacinate complex at low temperature $(\eta=20 \%)$ is the double of the value at room temperature $(\eta=9 \%)$. The low values of $\eta$ reflect the luminescence quenching of the $\mathrm{Eu}^{3+}$ ion. Such behavior agrees with what is observed for some $\mathrm{Eu}^{3+}$-aromatic carboxylate coordination compounds reported in the literature. ${ }^{31}$

The $A_{\text {nrad }}$ values of the complexes (4) and (7) are very low and practically independent of temperature. Although the low values of $A_{\text {rad }}$ as compared with the $\mathrm{Eu}^{3+}-\beta$-diketoante complexes reported in the literature, ${ }^{30}$ which present values of $A_{\text {rad }}$ close to $1000 \mathrm{~s}^{-1}$, suggest that the low values of $A_{\text {nrad }}$ contribute for the augment of emission quantum efficiency $(\eta)$ in more than six times as compared with hydrated complex (1) (Table 1).

The Judd-Ofelt intensity parameters $\left(\Omega_{2}\right.$ and $\left.\Omega_{4}\right)$ present very similar values and reflect the small ratio between intensities of the ${ }^{5} \mathrm{D}_{0} \rightarrow{ }^{7} \mathrm{~F}_{2}$ and ${ }^{5} \mathrm{D}_{0} \rightarrow{ }^{7} \mathrm{~F}_{4}$ transitions (Table 1). Moreover, the $\Omega_{2}$ values change only slowly when water molecules are substituted by neutral ligands in the first coordination sphere of the $\mathrm{Eu}^{3+}$ ion, indicating that the parameter is mostly influenced by small angular

Table 1. Experimental intensity parameters $\left(\Omega_{\lambda=2,4}\right)$, radiative rate $\left(A_{\text {rad }}\right)$, non-radiative rate $\left(A_{\text {nrad }}\right)$, lifetime $(\tau)$ and emission quantum efficiency $(\eta)$ of the ${ }^{5} \mathrm{D}_{0}$ emitting level determined for the $\mathrm{Eu}^{3+}$ complexes $(\mathbf{1}, \mathbf{4}$ and 7) recorded at 298 and $77 \mathrm{~K}$

\begin{tabular}{lcccccccc}
\hline Coordination compound & Temperature / K & $\mathrm{A}_{\text {rad }} / \mathrm{s}^{-1}$ & $\mathrm{~A}_{\text {rrad }} / \mathrm{s}^{-1}$ & $\Omega_{2} / 10^{-20} \mathrm{~cm}^{2}$ & $\Omega_{4} / 10^{-20} \mathrm{~cm}^{2}$ & $\tau / \mathrm{ms}$ & $\mathrm{A}_{\text {tot }} / \mathrm{s}^{-1}$ & $\eta / \%$ \\
\hline Eu(indo) ${ }_{3}\left(\mathrm{H}_{2} \mathrm{O}\right)_{3}(\mathbf{1})$ & 298 & 477 & 4786 & 10.2 & 8.2 & 0.19 & 5263 & 9 \\
& 77 & 391 & 1570 & 7.9 & 7.1 & 0.51 & 1961 & 20 \\
Eu(indo) $)_{3}($ bipy) (4) & 298 & 366 & 222 & 7.1 & 7.0 & 1.70 & 588 & 62 \\
& 77 & 360 & 239 & 6.6 & 7.6 & 1.67 & 599 & 60 \\
Eu(indo) $)_{3}$ (phen) (7) & 298 & 391 & 328 & 7.9 & 7.1 & 1.39 & 719 & 54 \\
& 77 & 337 & 317 & 6.9 & 5.3 & 1.53 & 654 & 51 \\
\hline
\end{tabular}


changes in the local coordination geometry. ${ }^{32-35}$ However, they are quite similar for $\mathrm{Eu}^{3+}$-indomethacinate complexes containing heterocyclic ligands.

\section{Luminescence spectra of the $\mathrm{Tb}^{3+}$}

Figure 8 shows the excitation spectra for $\mathrm{Tb}^{3+}$-indomethacinate complexes recorded at $77 \mathrm{~K}$ in the spectral range of $250-550 \mathrm{~nm}$. These spectra exhibit broad absorption bands with maxima at around $350 \mathrm{~nm}$ and a sharp absorption band located at $480 \mathrm{~nm}$ that reflect the indirect (via ligand) and direct excitation of the $\mathrm{Tb}^{3+}$ ion, respectively.

The emission spectra of $\mathrm{Tb}^{3+}$-indomethacinate complexes were recorded at 298 and $77 \mathrm{~K}$ in the spectral range of $450-700 \mathrm{~nm}$, under excitation on the intraligand

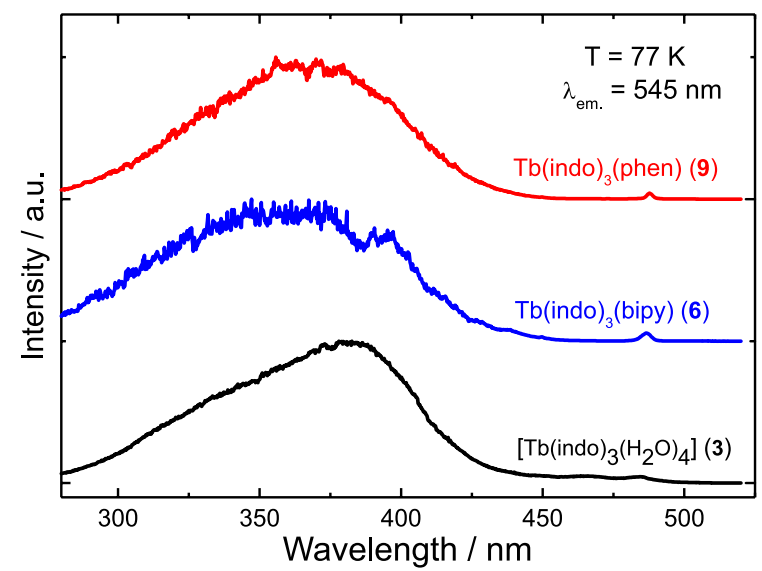

Figure 8. Excitation spectra of the $\mathrm{Tb}^{3+}$-complexes $(\mathbf{3}, \mathbf{6}$ and $\mathbf{9})$, in solid state, recorded at $77 \mathrm{~K}$ with emission monitored at $545 \mathrm{~nm}$.

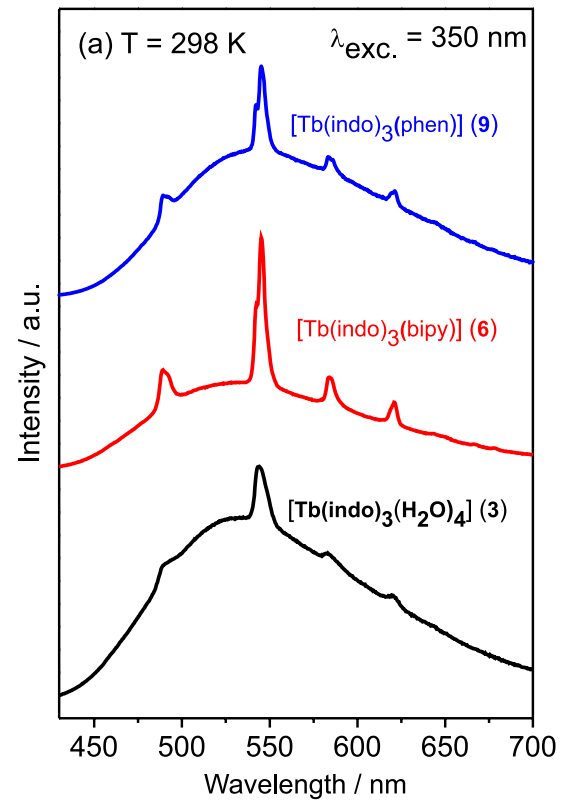

$\mathrm{S}_{0} \rightarrow \mathrm{S}_{1}$ transition (Figure 9). As shown in Figure 9a, all emission spectra measured at $298 \mathrm{~K}$ present a broad emission band due to the indomethacinate ligand that overlaps the sharp emission bands assigned to the intraconfiguration- $4 \mathrm{f}^{8}$ of the $\mathrm{Tb}^{3+}$ ion: ${ }^{5} \mathrm{D}_{4} \rightarrow{ }^{7} \mathrm{~F}_{6}(480 \mathrm{~nm}),{ }^{5} \mathrm{D}_{4} \rightarrow{ }^{7} \mathrm{~F}_{5}(545 \mathrm{~nm})$, ${ }^{5} \mathrm{D}_{4} \rightarrow{ }^{7} \mathrm{~F}_{4}(584 \mathrm{~nm}),{ }^{5} \mathrm{D}_{4} \rightarrow{ }^{7} \mathrm{~F}_{3}(621 \mathrm{~nm})$, and ${ }^{5} \mathrm{D}_{4} \rightarrow{ }^{7} \mathrm{~F}_{2}$ $(650 \mathrm{~nm})$. The energy gap $\Delta \mathrm{E}\left(\mathrm{T}_{\text {indomethacinate }}-{ }^{5} \mathrm{D}_{4}\right)$ is only approximately $1000 \mathrm{~cm}^{-1}$. These optical data indicate that the indomethacinate ligand is a better luminescence sensitizer for the $\mathrm{Eu}^{3+}$ than for the $\mathrm{Tb}^{3+}$ ion. This result is in according to Latva's empirical rule, which indicates that optimal sensitizing for $\mathrm{Tb}^{3+}$ and $\mathrm{Eu}^{3+}$ luminescence requires an energy gap between donor and acceptor states in gate $2100-4500 \mathrm{~cm}^{-1}$. This fact indicates that energy back-transfer process from the $\mathrm{Tb}^{3+}$ ion to indo ligand is operative, acting as a luminescence quenching channel.

The CIE (International Comission on Illumination) color coordinates of the $\mathrm{Eu}^{3+}$ - and $\mathrm{Tb}^{3+}$-indomethacinate complexes measured from emission spectra ${ }^{35}$ recorded at 298 and $77 \mathrm{~K}$ are presented in Figure 10. According to these results, the emission color of the $\mathrm{Eu}^{3+}$ complex (1) is tunable from pink to red when temperature is lowed. This behavior reflects the complete quenching of the phosphorescence band from indomethacinate coordinated ligand for the emission spectrum recorded at $77 \mathrm{~K}$. Besides, taking into consideration that the emission spectra of the $\mathrm{Eu}^{3+}$ coordination compounds (4) and (7) recorded at both temperatures are dominated by the intraconfigurational- $4 \mathrm{f}^{6}$ narrow emission bands centered on the $\mathrm{Eu}^{3+}$ ion, the $\mathrm{CIE}$ color coordinates are located in the red region of CIE

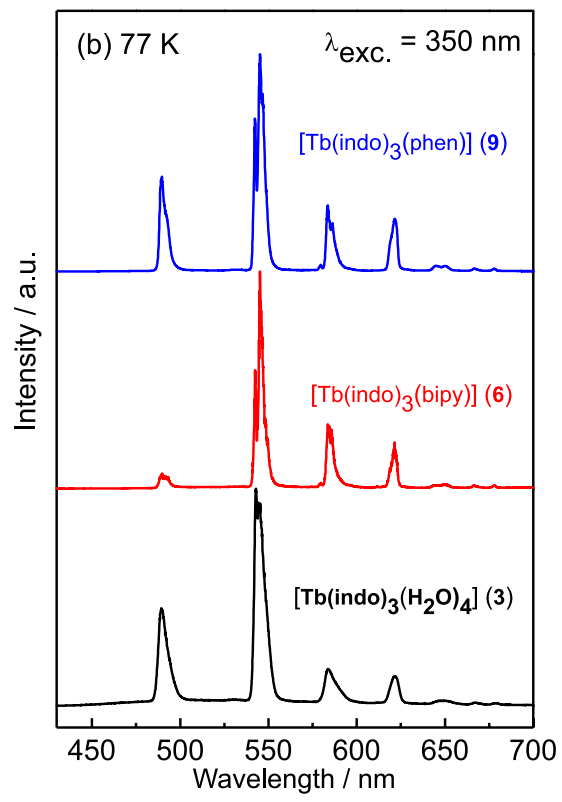

Figure 9. Emission spectra of the $\mathrm{Tb}^{3+}$ complexes $(\mathbf{3}, \mathbf{6}$ and $\mathbf{9})$, in solid state, recorded at (a) 298 and (b) $77 \mathrm{~K}$, under excitation on the singlet state $\mathrm{S}_{1}$ of the indomethacinate ligand at $350 \mathrm{~nm}$. 
chromaticity diagram, as expected. Thus, the europium complexes exhibit pure red emission color.

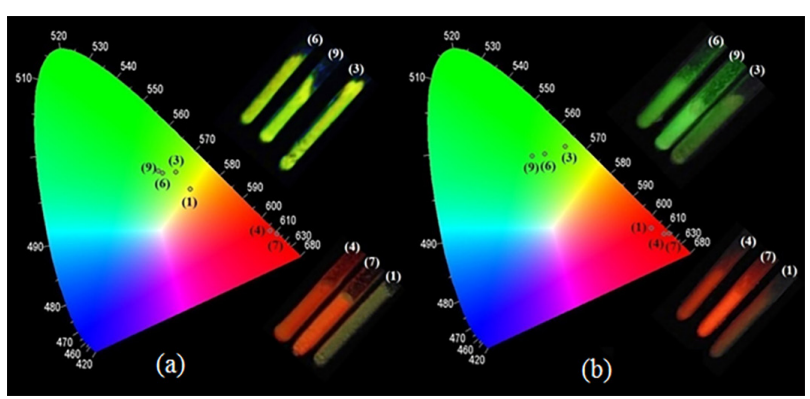

Figure 10. CIE chromaticity diagram presenting $(x, y)$ color coordinates for $\mathrm{Eu}^{3+}$ and $\mathrm{Tb}^{3+}$ complexes at (a) room temperature and (b) liquid nitrogen temperature, under excitation at $350 \mathrm{~nm}$. Photographs of the $\mathrm{RE}^{3+}$ complexes (insert) taken with a digital camera displaying the green and red emissions under UV irradiation lamp at $365 \mathrm{~nm}$.

As mentioned above, all emission spectra of the $\mathrm{Tb}^{3+}$-indomethacinate compounds recorded at $298 \mathrm{~K}$ exhibit the high intense phosphorescence band assigned to $\mathrm{T}_{1} \rightarrow \mathrm{S}_{0}$ transition from indomethacinate ligand (Figure 9a). Therefore, they present CIE coordinates color in the green-yellow region. On the other hand, the green emission colors displayed by these complexes at $77 \mathrm{~K}$ reflect the dominating intensities of the narrow emission bands arising from the intraconfigurational- $4 f^{8}$ transitions centered on the $\mathrm{Tb}^{3+}$ ion (Figure 9b).

Excitation spectra of the solid solutions $\mathrm{Eu}_{0.5} \mathrm{~Tb}_{0.5}(\text { indo })_{3}\left(\mathrm{H}_{2} \mathrm{O}\right)_{3}$ and $\mathrm{Eu}_{0.5} \mathrm{~Tb}_{0.5}(\text { indo })_{3}(\mathrm{~L})$, where L: phen or bipy, have been also recorded at $77 \mathrm{~K}$ in order to investigate the monomeric or polymeric nature of the synthesized systems (Figure S7 in the SI section). These systems were prepared based on the experimental procedures for pure complexes, using equimolar mixtures of $\mathrm{Eu}^{3+}$ and $\mathrm{Tb}^{3+}$ ions. All excitation spectra (Figure S7 in the SI section) of the solid solutions recorded under emissions monitored at $679 \mathrm{~nm}\left({ }^{5} \mathrm{D}_{0} \rightarrow{ }^{7} \mathrm{~F}_{4}\right.$ transition of the $\mathrm{Eu}^{3+}$ ion exhibit a narrow band at $487 \mathrm{~nm}$, which corresponds to the intraconfigurational ${ }^{5} \mathrm{~F}_{6} \rightarrow{ }^{5} \mathrm{D}_{4} \mathrm{~Tb}^{3+}$-centered transition. This result suggests that RE-indomethacinate complexes are dinuclear or polymeric systems. Similar results were also observed for RE-ibuprofen complexes containing donor nitrogen ligands ${ }^{36,37}$ and for RE-dipivaloyl complexes with tppo as neutral ligand. ${ }^{38}$

\section{Conclusions}

Herein, nine novel rare earth indomethacinate complexes were successfully prepared using simple synthetic routes. The coordination compounds presenting formulas $\mathrm{RE}(\text { indo })_{3}\left(\mathrm{H}_{2} \mathrm{O}\right)_{\mathrm{x}}, \mathrm{RE}(\text { indo })_{3}$ (bipy) and $\mathrm{RE}(\text { indo })_{3}$ (phen)
$\left(\mathrm{RE}: \mathrm{Eu}^{3+}, \mathrm{Gd}^{3+}\right.$ and $\mathrm{Tb}^{3+}$, indo: indomethacinate ligand, bipy: 2,2'-bipyridine, and phen: 1,10-phenanthroline, $\mathrm{x}=3$ for $\mathrm{Eu}^{3+}$ and $\mathrm{Gd}^{3+}$ complexes, and $\mathrm{x}=4$ for $\mathrm{Tb}^{3+}$ complex) were characterized by elemental analysis of $\mathrm{C}, \mathrm{N}$ and $\mathrm{H}$, thermogravimetric analysis and infrared spectroscopic data. Based on photoluminescent parameters, non-radiative rates $\left(\mathrm{A}_{\text {nrad }}\right)$ were drastically decreased when water molecules were substituted by heterocyclic ligands, which improved significantly the emission quantum efficiencies of the complexes. On the other hand, the radiative rates $\left(\mathrm{A}_{\mathrm{rad}}\right)$ and the Judd-Ofelt $\Omega_{\lambda=2,4}$ parameters were almost insensitive to the coordination changes.

Referring to the coordination of heterocyclic ligands, the intramolecular energy transfer processes in the $\mathrm{RE}^{3+}$ coordination compounds were also improved. The spectroscopic results indicated that $T_{1}$ excited states of the heterocyclic ligands play an important role as an intermediate state on the luminescence sensitization of the $\mathrm{Eu}^{3+}$ ion by the indomethacinate ligand. Finally, the properties of $\mathrm{RE}^{3+}$-indomethacinate complexes in the solid state described in this work are highly appropriate for light conversion molecular devices, such as those used as luminescent markers for bioassays and bioimage fields.

\section{Supplementary Information}

FTIR spectra, thermogravimetric data and luminescence spectra for compounds $2,5,8,3,6$ and 9 are available free of charge at http://jbcs.sbq.org.br as PDF file.

\section{Acknowledgments}

The authors are grateful for the financial support from the $\mathrm{CNPq}$ (Conselho Nacional de Desenvolvimento Científico e Tecnológico), INCT-INAMI (CNPq), CNPqFACEPE-PRONEX, CAPES, FAPESP (Fundação de Amparo à Pesquisa do Estado de São Paulo), Financiadora de Estudos e Projetos (FINEP), PET/IFPB (Programa de Educação Tutorial / Instituto Federal de Educação, Ciência e Tecnologia da Paraíba).

\section{References}

1. Weder, J. E.; Dillon, C. T.; Hambley, T. W.; Kennedy, B. J.; Lay, P. A.; Biffin, J. R.; Regtop, H. L.; Davies, N. M.; Coord. Chem. Rev. 2002, 232, 95.

2. Kostova, I.; Curr. Med. Chem. Anti-Cancer Agents 2005, 5, 591.

3. Lopez-Sandoval, H.; Londono-Lemos, M. E.; Garza-Velasco, R.; Poblano-Melendez, I.; Granada-Macias, P.; Gracia-Mora, I.; Barba-Behrens, N.; J. Inorg. Biochem. 2008, 102, 1267. 
4. Miodragovic, D. U.; Bogdanovic, G. A.; Miodragovic, Z. M.; Radulovic, M. D.; Novakovic, S. B.; Kaludjerovic, G. N.; Kozlowski, H.; J. Inorg. Biochem. 2006, 100, 1568.

5. Devereux, M.; McCann, M.; Shea, D. O.; Kelly, R.; Egan, D.; Deegan, C.; Kavanagh, K.; McKee, V.; Finn, G.; J. Inorg. Biochem. 2004, 98, 1023.

6. Takeuchi, T.; Bottcher, A.; Quezada, C. M.; Meade, T. J.; Bioorg. Med. Chem. 1999, 7, 815.

7. Epstein, S. P.; Wallace, J. A.; Cornea 1998, 17, 550.

8. Mothilal, K. K.; Karunakaran, C.; Rajendran, A.; Murugesan, R.; J. Inorg. Biochem. 2004, 98, 322.

9. Teslyuk, O. I.; Bel'tyukova, S. V.; Yegorova, A. V.; Yagodkin, B. N.; J. Anal. Chem. 2007, 629, 330.

10. Terreno, E.; Castelli, D. D.; Viale, A.; Aime, S.; Chem. Rev. 2010, 110, 3019.

11. Tweedle, M. F.; Acc. Chem. Res. 2009, 42, 958.

12. Horrocks, W. D.; Acc. Chem. Res. 1981, 14, 384.

13. Zhou, X. J.; Zhao, X. Q.; Wang, Y. J.; Wu, B.; Shen, J.; Li, L.; Li, Q. X.; Inorg. Chem. 2014, 53, 12275.

14. Kaczmarek, M.; J. Fluoresc. 2011, 2201, 21.

15. Refat, M. S.; Mohamed, G. G.; Ibrahim, M. Y. S.; Killa, H. M. A.; Fetooh, H.; Russ. J. Gen. Chem. 2013, 83, 2479.

16. Nolasco, M. M.; Vaz, P. D.; Carlos, L. D.; New J. Chem. 2011, $35,2435$.

17. Xu, H.; Huang, W.; J. Photochem. Photobiol., A 2011, 217, 213.

18. Li, X. N.; Si, Z. J.; Zhou, L.; Liu, X. J.; Zhang, H. J.; Phys. Chem. Chem. Phys. 2011, 11, 9687.

19. Bemquerer, M. P.; Bloch, C.; Brito, H. F.; Teotonio, E. E. S.; Miranda, M. T. M.; J. Inorg. Biochem. 2002, 91, 363.

20. Deacon, G. B.; Phillips, R. J.; Coord. Chem. Rev. 1980, 33, 227.

21. Nakamoto, K.; Infrared and Raman Spectra of Inorganic and Coordination Compounds, Applications in Coordination, Organometallic, and Bioinorganic, $6^{\text {th }}$ ed.; Wiley: New Jersey, USA, 2009.

22. Gerasimova, T. P.; Katsyuba, S. A.; Dalton Trans. 2013, 42, 1787.

23. Chen, Y. J.; Xing, Z. F.; Cao, S.; Wang, Y.; J. Rare Earths 2016, 34, 240.

24. Lin, M. J.; Wang, X. P.; Tang, Q.; Ling, Q.; J. Rare Earths 2013, 31,950 .

25. Holz, R. C.; Thompson, L. C.; Inorg. Chem. 1993, 32, 5251.
26. Resende-Filho, J. B. M.; Silva, J. C.; Vale, J. A.; Brito, H. F.; Faustino, W. M.; Espínola, J. G. P.; Felinto, M. C. F. C.; Teotonio, E. E. S.; J. Braz. Chem. Soc. 2014, 25, 2080.

27. Kisel, K. S.; Linti, G.; Starova, G. L.; Sizov, V. V.; Melnikov, A. S.; Pushkarev, A. P.; Bochkarev, M. N.; Grachova, E. V.; Tunik, S. P.; Eur. J. Inorg. Chem. 2015, 2015, 1734.

28. de Sá, G. F.; Malta, O. L.; Mello-Donegá, C.; Simas, A. M.; Longo, R. L.; Santa-Cruz, P. A.; Silva-Jr, E. F.; Coord. Chem. Rev. 2000, 196, 165.

29. Niyama, E.; Teotonio, E. E. S.; Brito, H. F.; Brito, G. E. S.; Cremona, M.; Reyes, R.; Felinto, M. C. F. C.; Spectrochim. Acta, Part A 2005, 61, 2643.

30. Horrocks-Jr, W. W.; Sudnick, D. R.; Acc. Chem. Res. 1981, 14, 384.

31. Teotonio, E. E. S.; Brito, H. F.; Viertler, H.; Faustino, W. M.; Malta, O. L.; de Sá, G. F.; Felinto, M. C. F. C.; Santos, R. H. A.; Polyhedron 2006, 25, 3488.

32. Brito, H. F.; Malta, O. L.; Felinto, M. C. F. C.; Teotonio, E. E. S. In Luminescence Phenomena Involving Metal Enolate, vol. 1; Zabicky, J., ed.; John Wiley \& Sons: Chichester, UK, 2009.

33. Silva, H. R. M.; Fonseca, M. G.; Espínola, J. G. P.; Brito, H. F.; Faustino, W. M.; Teotonio, E. E. S.; Eur. J. Inorg. Chem. 2014, 11, 1914.

34. Teotonio, E. E. S.; Brito, H. F.; de Sá, G. F.; Felinto, M. C. F. C.; Santos, R. H. A.; Fuquen, R. M.; Costa, I. F.; Kennedy, A. R.; Gilmore, D.; Faustino, W. M.; Polyhedron 2012, 38, 58.

35. Santa-Cruz, P. A.; Teles, F. S.; SpectraLux Software, version 2.0; Ponto Quântico Nanodispositivos/RENAMI: Recife, PE, Brasil, 2003.

36. Marques, L. F.; Cuin, A.; Ribeiro, S. J. L.; Machado, F. C.; Inorg. Chim. Acta 2016, 441, 67.

37. Marques, L. F.; Correa, C. C.; Garcia, H. C.; Ribeiro, S. J. L.; Dutra, J. D. L.; Freire, R. O.; Machado, F. C.; J. Lumin. 2014, 148, 307.

38. Miranda, Y. C.; Pereira, L. L. A. L.; Barbosa, J. H. P.; Brito, H. F.; Felinto, M. C. F. C.; Malta, O. L.; Faustino, W. M.; Teotonio, E. E. S.; Eur. J. Inorg. Chem. 2015, 2015, 3019.

Submitted: February 1, 2017

Published online: May 3, 2017 